\title{
Application of Big Data in the Promotion of Fast Selling Products
}

\author{
Wenxin Cui ${ }^{1}$ \\ ${ }^{1}$ Supply Chain Management \\ Eli Broad College of Business, Michigan State University, East Lansing, United States, 48824
}

\begin{abstract}
In the traditional marketing mode of fast-selling products, the sales mode of physical stores is adopted. However, in the background of the current big data era, it is a trend to optimize the promotion form by applying big data technology. Therefore, this paper puts forward the application research of big data in the promotion of fast-selling products. This paper makes an indepth study on big data technology and commodity marketing. It is believed that there is a lot of information hidden behind the information data, and the application of big data technology pays more attention to consumer behavior than before. In this paper, according to the characteristics of fast-selling products promotion activities, combined with big data technology, the effect evaluation model are established, which can better solve the shortcomings of traditional promotion activities which are difficult to evaluate. And according to the actual needs of the promotion of fast-selling products, targeted optimization is carried out. In order to further verify the data analysis ability of big data technology in the promotion of fast selling products, this paper establishes the corresponding investigation experiment. The experimental data show that big data technology can better analyze the actual effect of various promotion tools and promotion strategies, provide technical support for enterprises before and after the promotion of fast-selling products, and facilitate enterprises to adjust strategies and summarize experience. The analysis shows that big data technology has brought a variety of convenience to the promotion activities, which not only broadens the sales channels, but also provides a new basis for the decision-making of enterprises.
\end{abstract}

\section{Introduction}

The rapid development of information technology has created a new way of life for consumers. As a businessman, who can use the power of various technologies, especially the power of data, can win the competition. At present, big data has gradually developed into an important element of modern production management, and will be the main application field of Chinese enterprises in the next market competition [1-3]. At present, big data and Internet technology are developing at the same time. On the one hand, commercial data needs to become more and more unprecedented; on the other hand, new products and customer service requirements need to be more refined and personalized. Enterprises must carry out various personalized marketing for each specific target consumer group [4-5].

In addition, behind a large number of data sources, there are radical changes in the traditional human behavior analysis methods. In the past, business decisions relied more on the results of experience, while in the era of big data, decision-making relied on comprehensive data analysis. In the context of big data, changes in consumer behavior characteristics are easier to analyze and understand [6-8]. Big data not only changes the traditional retail business models of physical retailers, but also makes it more difficult to match the needs of a new retail marketing environment in the new retail marketing market environment. It is necessary to re understand the retail big data technology and reconstruct the strategic system of the traditional retail industry [9-10].

This paper deeply studies the main models of the promotion of fast-selling products in China, and finds that there are some practical problems in the actual operation, such as the effect is difficult to evaluate, the promotion methods are backward, and the promotion channels are narrow. This shows that in the era of big data, the traditional promotion methods of fast-selling products are no longer applicable, and timely optimization and improvement are needed to keep pace with the development of the times. Therefore, this paper puts forward the application research of big data in the promotion of fast-selling products, hoping to reform and improve the existing promotion mode of fast-selling products through the optimization and improvement measures in this paper, so as to improve the efficiency of enterprises. Aiming at the existing problems, this paper gives specific optimization and improvement measures, including the establishment of promotion effect evaluation model based on big data technology, the integration of variable QR code and big data technology, and the use of big data to mine the data of new retail, etc. Through the scheme of this paper, it further improves the actual effect of enterprises in the promotion of fast selling products. In 
addition, in order to further verify the actual effect of this scheme, this paper carried out relevant investigation and research. The results show that the promotion scheme of fast selling products based on big data technology can better analyze the user behavior and play a key role in the decision-making of promotion activities.

\section{Meaning of Promotion and Big Data Marketing}

\subsection{Connotation of Promotion}

In the marketing activities of modern enterprises, it is necessary to stimulate consumers to buy through various means of promotion. In marketing theory, promotion is an important part of marketing mix strategy. Broadly speaking, it refers to the marketing means adopted by enterprises to promote sales, including personnel promotion and public relations. Its purpose is to attract consumers' attention, stimulate their purchase desire, and finally achieve the goal of purchase. In the narrow sense, promotion only means that in order to promote sales growth, enterprises provide various short-term incentives to promote sales growth. Most of the domestic scholars' research on promotion is mainly from a narrow point of view. However, no matter what the form of promotion is, its essence is the information exchange between enterprises and consumers.

\subsection{Overview of Big Data and Marketing}

Big data is only an abstract concept, and the specific definition has not been completely unified. Generally speaking, big data refers to a large amount of data that ordinary computing software or tools can't process correctly within a reasonable time. Marketing model can be divided into three stages: traditional integrated marketing, network marketing, big data marketing. In the traditional marketing activities, the activities of marketers are usually carried out continuously in the actual space, so consumers can really feel the products they experience, and the environment in the market is therefore regional. Internet marketing has made it possible for Chinese consumers to purchase all kinds of necessary commodities directly by using various digital information on the Internet. The concept of consumers has changed from the central concept of traditional products to more satisfying the actual needs of consumers. Big data marketing is a new marketing method with the development of big data technology and the improvement of computer interaction ability.

\section{Survey Method of User Behavior Analysis Based on Big Data Technology}

In Shaanxi, Gansu, Zhejiang, Beijing, Hunan and Jiangxi, 260 questionnaires were distributed, 100 were distributed on site, and 97 valid answers were recovered; 160 online questionnaires were distributed online, 151 valid questionnaire answers were recovered, and 248 questionnaires were collected. The on-site distribution is mainly conducted in Beijing Normal University, while the online distribution is mainly conducted in other regions. The questionnaire was distributed to the respondents through the website, and the specific situation was clearly explained with the respondents before the survey. In addition, mandatory and anti-duplicate settings are added to the website to improve the quality of the questionnaire. The main information of the respondents is shown in Table 1 . With the exception of a very small number of graduate students, there is little extra income in the survey, and the number of students and students in school is almost $50 \%$.

Table 1: main information of subjects in this survey.

\begin{tabular}{|c|c|c|c|}
\hline Attribute & Classification & Number of people & Total \\
\hline \multirow{2}{*}{ Gender } & male & 117 & \multirow{2}{*}{248} \\
\hline & female & 131 & \\
\hline \multirow{4}{*}{ Education } & below high school & 12 & \multirow{4}{*}{248} \\
\hline & junior college & 74 & \\
\hline & undergraduate & 93 & \\
\hline & graduate student & 69 & \\
\hline \multirow{5}{*}{ Income } & less than 1000 yuan & 129 & \multirow{5}{*}{248} \\
\hline & $1000-2000$ yuan & 68 & \\
\hline & $2000-4000$ yuan & 36 & \\
\hline & $4000-6000$ yuan & 10 & \\
\hline & over 6000 & 5 & \\
\hline
\end{tabular}

\section{Discussion}

\subsection{Analysis of Promotion Effect Based on Big Data Technology}

(1) Analysis on the proportion of consumers' attitude response to different promotion tools

According to the survey results in Figure 1, in terms of attitude influence, price reduction promotion can attract consumers' attention most. The order of attention is: product stacking, price reduction, gifts, selling point explanation. The order of interest is: price reduction, gifts, merchandise stacking and selling point explanation. What kind of promotion do you like to buy products in order: price reduction, gifts, product stacking, and selling point explanation? The analysis shows that different promotion methods and the application effect of promotion tools can be calculated and estimated through big data technology, 
and businesses can formulate reasonable and effective promotion strategies according to their own needs when promoting.

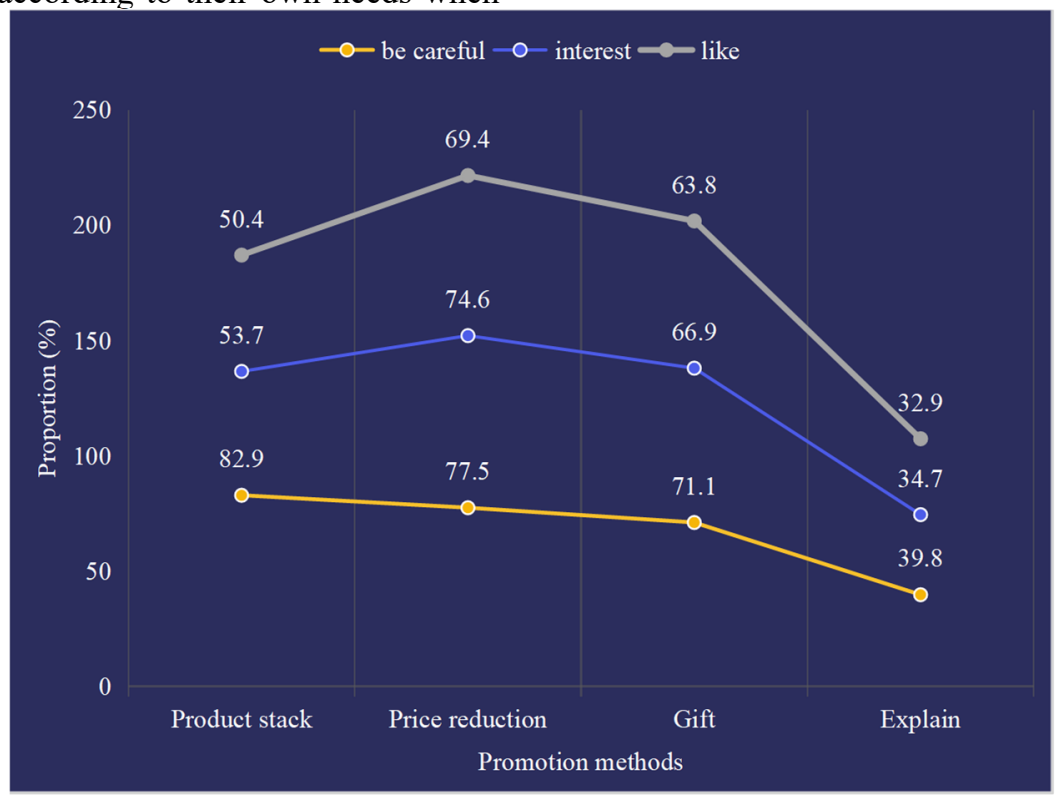

Figure 1: Analysis on the proportion of consumers' attitude response to different promotion tools

(2) Analysis on the proportion of consumers' attention to the real benefits that enterprises bring to response to different promotion strategies

As can be seen from Figure 2, the results show that the proportion of consumers affected by price reduction is the highest, and the order of purchase timing is: price reduction, gift, explanation of selling points and product stacking. In terms of quantity, orders are divided into: price reduction, gifts, explanation of selling points and stacking of goods. To sum up, consumers pay more consumers in the process of purchasing FMCG. Price reduction and gift giving are the most practical interests of consumers. In terms of conversion rate, orders are: price reduction, gifts, goods stacking, selling point explanation. In terms of loyalty, orders include price reduction, gifts, merchandise stacking and selling point explanation, among which price reduction has the greatest impact on brand loyalty.

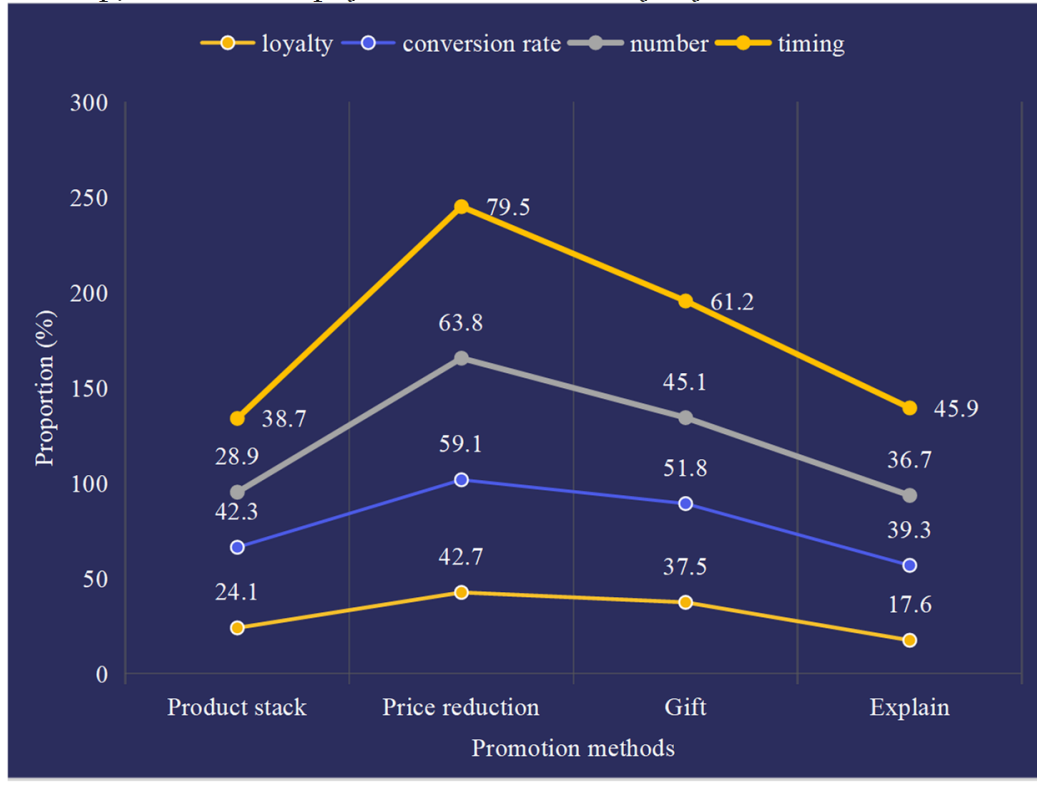

Figure 2: Analysis on the proportion of consumers' response to different promotion strategies

\subsection{Model Estimation}

Assuming that consumer $n$ purchases a product from a choice set consisting of $J$ commodities, the formula for calculating the statistical likelihood is as follows:

$$
L_{n}=\prod_{j=1}^{J} P_{n j}^{v n j}, j \in C, j=1, \cdots, J
$$

For $N$ consumers, the formula of likelihood is as follows:

$$
L=\prod_{n=1}^{N} \prod_{j=1}^{J} P_{n j}^{y n j}, j \in C, j=1, \cdots, J, n=1, \cdots, N
$$

According to the statistical maximum likelihood method, the maximum likelihood value is used to solve the model parameters. However, in mathematical statistics, the maximum likelihood value itself is not the direct 
maximum, but a direct maximum of the logarithmic likelihood value. At the same time, the log likelihood method also has some advantages in macro statistics. The normal parameter distribution of the maximum likelihood method has the macroscopic statistics; the efficiency enhancement and the parameter tend to the normal logarithmic distribution statistical consistency. The natural $\log$ likelihood is calculated as follows:

$$
L L=\sum \sum y n j^{\ln (p n j)}, j \in C, j=1, \cdots j, n=1, \cdots, N
$$

By substituting formula (1) into formula (3) and maximizing $L L$, we can obtain the solution of the parameter.

\subsection{Integration of Variable QR Code and Big Data Technology}

The e-commerce platform, distribution system, customer data acquisition and other integrated into a unified terminal promotion and application platform to realize real-time monitoring of sales situation and direct payment to the terminal. Variable two-dimensional code technology uses a unique two-dimensional code generation algorithm. Different from the traditional two-dimensional code, the two-dimensional code of each commodity is different. The special disorder structure of the variable QR code reduces the threat of traditional malicious theft brush, and ensures the safety of goods. With the two-dimensional code as the carrier, the commodity information is tracked, inquired and managed. The commodity has a unique twodimensional code. Based on this, the commodity information management system is established. By scanning the QR code of the user's mobile phone for promotion, the promotion procedure is simpler, and the promotion participation rate of consumers is effectively improved. Through the powerful back-end operating system, complete the basic information collection of consumers participating in promotion activities, and carry out professional processing to prepare for the secondary marketing.

\subsection{Mining New Retail Data with Big Data}

In the development of new retail industry, a large number of customer data will be generated. Strengthening the mining and utilization of these data can help enterprises find useful information from the data in time, and then promote the efficient development of marketing. Data mining can be carried out from personalized tag system and customer classification. Personalized label refers to the targeted label that enterprises make for consumers according to the existing consumer data. At present, personality tags are divided into attribute tags and behavior tags. Attribute tags mainly refer to the basic information of consumers, including the names and contact information of consumers; behavior tags are mainly used to mine and record the consumption of consumers, such as the types of products purchased and the frequency of purchase. Customer classification is mainly based on the customer's personality tag, which classifies customer information and forms a perfect customer classification system.

\subsection{Precision Marketing}

For the current marketing, the value of big data in intelligent data mining is mainly reflected in that the accuracy of calculation data can be improved through large data models and tools. In the marketing process, big data technology can play an important role in data collection. In the marketing process, the use of big data technology to locate more accurate consumer groups, targeted at different consumer groups for accurate advertising and promotion, which is conducive to the long-term economic growth of enterprises. Enterprises can accurately locate customers through big data technology, timely adjust unreasonable marketing methods, and finally establish a more suitable model for enterprise marketing and development, so that enterprise products can be promoted and sold to a greater extent.

\section{Conclusions}

In this paper, in the application research of big data in the promotion of fast-selling products, the main promotion mode and characteristics of fast-selling products are deeply studied. At present, in the promotion activities of fast-selling products, the traditional promotion mode of physical stores is still the main way, and the promotion effect is not ideal through pushing, stacking goods, and explaining by sales personnel. This paper analyzes that in the era of big data, information technology has changed people's living habits, and the promotion of fast-selling products should also use advanced big data technology to effectively mine massive user information, so as to provide help for decision-making of promotion activities. The promotion effect evaluation model based on big data technology proposed in this paper, to a certain extent, makes up for the shortcomings of the traditional promotion mode. Especially after the adoption of smart app and other technologies, it greatly broadens the promotion channels. With the application of Internet technology, promotion advertising becomes more accurate, which improves the attractiveness of activities and brings higher benefits to enterprises. The results show that although the development of Internet and data technology has affected the sales of physical stores to a certain extent, businesses can turn this disadvantage into advantages after making full use of modern technology, which will help the long-term development of enterprises.

\section{References}

[1] Yoon, Hyun Shik, \& Occena, Luis G. (2015). Influencing factors of trust in consumer-to-consumer electronic commerce with gender and age. International Journal of Information Management, 35(3), 352-363.

[2] Shim, J. P., Koh, J., Fister, S., \& Seo, H. Y. (2016). Phonetic analytics technology and big data: realworld cases. Communications of the ACM, 58(2), 84-90. 
[3] Luis Emilio AlvarezDionisi. (2017). Envisioning skills for adopting, managing, and implementing big data technology in the 21 st century. International Journal of Information Technology \& Computer ence, 9(1), $18-25$.

[4] Gupta, B., Nath, R., Gopal, G., \& Kartik, K. (2016). An efficient approach for storing and accessing small files with big data technology. International Journal of Computer Applications, 146(1), 36-39.

[5] Ekong, E. E., Adiat, Q. E., Ejemeyovwi, J. O., \& Alalade, A. M. (2019). Harnessing big data technology to benefit effective delivery and performance maximization in pedagogy. International Journal of Civil Engineering and Technology, 10(1), 2170-2178.

[6] Yang, J., Qiao, Y., Zhang, X., He, H., Liu, F., \& Cheng, G. (2017). Characterizing user behavior in mobile internet. IEEE Transactions on Emerging Topics in Computing, 3(1), 95-106.

[7] Roostika, R. (2016). The effect of perceived service quality and trust on loyalty: customer's perspectives on mobile internet adoption. International Journal of Innovation and Technology Management, 2(4), 286291.

[8] Izquierdo-Yusta, A., Olarte-Pascual, C., \& ReinaresLara, E. (2015). Attitudes toward mobile advertising among users versus non-users of the mobile internet. Telematics \& Informatics, 32(2), 355-366.

[9] Jesús Fernando Lampón Caride, \& Ana Isabel Martínez Senra. (2015). Marketing en internet: el sector vitivinícola gallego. Revista De Estudios Regionales, 02(73), 107-129.

[10] Zhang Yiming. (2018). Analysis of internet marketing strategy based on consumer demand intention. Value Engineering, 007 (015), 77-78. 